\title{
ABORDAGEM PRAgMAlinguística DE TEXTOS BÍblicos *
}

\author{
Pragmalinguistic Approach to the Biblical Texts
}

Clodomiro de Sousa e Silva **

RESUMO: Este estudo visa a estabelecer uma base conceitual-teórica à análise de um texto bíblico em perspectivas comunicativa e pragmática. A Escritura e a Tradição da Igreja ressaltam, há tempo, o valor pragmático da Palavra de Deus, que não retorna ao seu Autor sem ter alcançado o seu propósito (Is 55,11). No entanto, a aplicação da pragmalinguística ao estudo dos textos bíblicos e aos seus relativos contextos de leitura é um fenômeno recente na exegese bíblica. A pesquisa se desenvolve a partir das investigações e publicações de renomados exegetas que, nas últimas três décadas, têm se dedicado à tarefa de escrever as primeiras páginas da linguística pragmática em âmbito bíblico.

PALAVRAS-CHAVE: Abordagem. Pragmalinguística. Comunicação. Texto. Bíblia.

ABSTRACT: This exposition aims to establish a conceptual-theoretical basis for the analysis of a biblical text from the communicative and pragmatic perspectives. The pragmatic value of the Word contained in the Scripture is not a recent discovery, because the Scripture itself explains that the Word of God does not return to its Author without having produced its effect (Isa 55:11). Nevertheless, what is recent is the pragmalinguistic application to the study of the biblical texts and to their relative contexts in which the reading occurs. This research counts on the collaboration of some renowned exegetes who, in the last three decades, have dedicated themselves to the task of writing the maiden pages of pragmatic linguistics within the biblical milieu.

KEYWORDS: Approach. Linguistics. Pragmatic. Text. Bible.

\footnotetext{
* O artigo é uma adaptação da tese doutoral "Apocalipse 12: uma leitura paradigmática do peregrinar cristão", primeiro tópico do capítulo 4 (4.1. Fundamentação teórica, p. 181-195), defendida junto à Faculdade Jesuíta de Filosofia e Teologia - FAJE / 2017.

** Instituto Católico de Estudos Superiores do Piauí, Teresina, Piauí, Brasil.
} 


\section{Introdução}

A cercar-se do texto bíblico como obra literária significa considerá-lo em 2010, p. 16). A exegese deve sim continuar a discutir o contexto existencial e a problemática literária dos textos bíblicos, mas com o olhar voltado para o presente. Afinal, a passagem da exegese à vida é necessária, a ponto de constituir uma verificação da validade de uma linha interpretativa. A tarefa do exegeta não cessa, portanto, depois que ele apontou as fontes, definiu as formas ou explicou os processos de composição de determinada passagem escriturística. Para além de tudo isso, o escopo do seu trabalho só terá sido alcançado quando ele tiver esclarecido o sentido do texto bíblico como Palavra atual de Deus (PONTIFÍCIA COMISSÃO BÍBLICA, 1994, III, C, 1).

O presente estudo tem por principal objetivo estabelecer um embasamento teórico ainda que elementar, à análise de um texto bíblico em perspectiva comunicativa e pragmática. Conta-se aqui como resultado das pesquisas e publicações de alguns renomados exegetas, que têm se dedicado, ao longo das três últimas décadas, a escrever as primeiras páginas da pragmalinguística aplicada à Bíblia. Esses estudiosos procuram integrar à exegese bíblica noções e conceitos colhidos de outras áreas do saber tais como a semiótica, a filosofia da linguagem, a moderna hermenêutica e a narratologia (PAZ; GRILLI; DILMANN, 1999, p. 5).

\section{Texto e comunicação}

Textos não nascem em um vazio, mas em um contexto de comunicação entre um emissor e um destinatário (BERGES, 1993, p. 83). A semiótica ${ }^{1}$ denomina "texto" qualquer comunicação realizada por meio de sinais. $\mathrm{O}$ texto verbal - objeto deste ensaio - pode ser sucintamente definido como uma unidade linguística estruturada e harmônica (um "tecido") em ordem à comunicação (GRILLI, 2002, p. 670). Seus elementos básicos constitutivos são a sua extensão - isto é, os limites da unidade comunicativa - e a sua coesão - ou seja, as articulações entre os sinais (PAZ; GRILLI; DILLMANN, 1999, p. 35). A extensão de um texto não é prescrita, podendo variar desde uma simples frase até uma obra literária completa. $\mathrm{O}$ mais importante é que ele possua sentido e organização interna, seja por coesão

\footnotetext{
${ }^{1}$ Na opinião de Massimo Grilli, dos três novos "métodos" de análise literária referidos pela Pontifícia Comissão Bíblica (1993) - retórica, narrativa e semiótica -, o terceiro é, certamente, o menos conhecido e menos difundido, mas também o mais atual e sugestivo (GRILLI, 2013, p. 525).
} 
sintática, seja por coerência semântica (GRILLI, 2002, p. 670). Um texto não é simplesmente um sistema fechado de sinais, que funcionam quase que independentemente do seu produtor e do seu destinatário, mas o ponto de contato entre ambos, o núcleo que libera a energia comunicativa (SIMIAN-YOFRE, 2000, p. 159).

O texto é uma comunicação cristalizada, uma mensagem codificada, elaborada por um emissor com a intenção de interpelar o destinatário e produzir nele um efeito (GRILLI, 1993, p. 448). O termo "comunicação" não está, porém, isento de ambiguidades, já que designa um processo complexo, no qual elementos diversos interagem mutuamente (OBARA, 2010 , p. 29). No entanto, pode-se definir um processo comunicativo, de maneira simplificada, como certo número de operações que procedem do interior para o exterior e vice-versa. De um lado encontra-se o emissor da mensagem que, depois de ter estabelecido o conteúdo a ser comunicado, busca dar-lhe a melhor forma possível, realizando assim um trabalho de codificação. Do outro lado está o destinatário da mensagem que trilha o caminho oposto, procedendo do exterior para o interior, em um trabalho de decodificação, que procura atingir o conteúdo a partir da expressão codificada (GRILLI, 2002, p. 659).

O modelo de comunicação proposto por Roman Jakobson, já célebre nos manuais de linguística, confere maior precisão à definição apresentada no parágrafo anterior. De acordo com o linguista russo, uma mensagem enviada por um emissor a um destinatário só produzirá o efeito desejado se houver: um contexto referencial apreensível pelo destinatário e que seja verbal ou susceptível de verbalização; um código total ou parcialmente comum ao emissor (codificador) e ao destinatário (decodificador) e, finalmente, um contato, isto é, um canal físico e uma conexão psicológica entre o emissor e o destinatário, que os capacite a entrar e a permanecer em comunicação. Em um ato de comunicação eficaz devem interagir, portanto, pelo menos seis elementos: emissor, destinatário, mensagem, código, contexto referencial e contato (JAKOBSON, 2008, p. 123).

\section{Comunicação escrita}

Uma vez que a exegese bíblica se debruça sobre textos escritos, é importante que se especifique a adaptação dos elementos do esquema comunicativo às peculiaridades da comunicação na forma escrita (OBARA, 2010, p. 34). O filósofo Paul Ricoeur tratou dessa questão em um artigo intitulado Speaking and writing, que se encontra na base do presente tópico. Ao analisar a passagem da oralidade à escrita, Ricoeur constata primeiramente que, na escrita, acontece a total manifestação de algo que está em um estado virtual, nascente e incipiente na fala viva, a saber, 
a separação entre o significado e o evento. $O$ autor propõe, então, partindo do modelo de comunicação descrito por Jakobson, inquirir acerca das alterações, transformações ou deformações que afetam a interação dos fatos ou as funções da comunicação, quando o discurso é posto por escrito (RICOEUR, 1976, p. 25-26).

Oralidade e escrita constituem duas formas distintas de manifestação da linguagem verbal. Embora ambas compartilhem do mesmo sistema linguístico, cada uma delas possui características e normas de funcionamento próprias. Na passagem da comunicação oral à escrita, a mudança mais óbvia concerne à relação mensagem-contato. Tal mudança irradia, porém, em todas as direções, afetando decisivamente os demais componentes do processo comunicativo. A primeira conexão a ser alterada é a da mensagem com o emissor que, por si, é uma de duas mudanças simétricas: as relações mensagem-emissor, por um lado, e mensagem-destinatário, por outro, "são profundamente transformadas, quando a relação face-a-face é substituída por uma relação mais complexa da leitura para a escrita, resultante da inscrição direta do discurso in littera" (RICOEUR, 1976, p. 29).

Na oralidade, a habilidade que o discurso possui de remeter-se ao sujeito falante - que pertence à situação de interlocução - apresenta um caráter de imediação. Consequentemente, a intenção do locutor e o sentido do discurso combinam de tal modo, que se torna praticamente a mesma coisa entender o que o locutor quer dizer e o que o seu discurso significa. Na escrita, ao invés, a intenção do autor e o significado do texto deixam de coincidir. A inscrição torna-se sinônimo de autonomia semântica do texto, que resulta da desconexão da intenção mental do autor e do significado verbal do texto. Daí por diante, passa a importar mais o que o texto significa do que aquilo que o autor quis dizer ao escrevê-lo. Essa "despsicologização" não implica, porém, que a noção de sentido do autor tenha perdido todo o seu significado, pois o texto permanece sendo um discurso proferido por alguém (RICOEUR, 1976, p. 29-30).

No outro extremo da cadeia comunicativa, a relação da mensagem textual com o leitor não é menos complexa do que é a relação com o autor. $\mathrm{O}$ texto escrito não é destinado a um "tu" determinado pela situação dialogal (como na oralidade), mas a um leitor desconhecido e, potencialmente, a qualquer um que saiba ler. Tal universalização da audiência é, no entanto, apenas potencial, pois um escrito dirige-se tão somente a um setor do público e chega aos seus leitores apropriados através de mecanismos que estão submetidos a regras sociais de exclusão e admissão. Mais uma vez, a dialética entre significado e evento é exibida em sua totalidade pela escrita. Por um lado, a autonomia semântica do texto permite a variedade de leitores potenciais e, por assim dizer, cria a audiência do texto. Por outro lado, é a resposta da audiência que faz o texto importante e, portanto, significante (RICOEUR, 1976, p. 31). 
A relação mensagem-código também se faz mais complexa na escrita, ainda que um tanto indiretamente. Tem-se em mente aqui a função dos gêneros literários enquanto produtores de "entidades linguísticas", isto é, de conjuntos orgânicos que não se reduzem ao mero acúmulo de frases. Um poema, uma narrativa ou um ensaio dependem de normas de composição que, a princípio, são indiferentes à oposição entre a fala e a escrita. Tais normas resultam da aplicação de formas dinâmicas a conjuntos de frases, para os quais a diferença entre a oralidade e a escrita não é essencial. Em vez disso, a especificidade dessas formas dinâmicas parece provir da aplicação ao discurso das categorias de "prática" e "obra". A linguagem é submetida às regras de uma espécie de habilidade artística, que permite falar de produção, de obras de arte e, por extensão, de "obras de discurso" A escrita desempenha um papel decisivo precisamente na aplicação das categorias de prática, técnica e obra ao discurso. A escrita como suporte material, a autonomia semântica do texto e todos os traços relatados da exterioridade característica da escrita ajudam a fazer da linguagem a matéria de uma habilidade artística específica. Graças à escrita, as obras de linguagem tornam-se tão autônomas quanto as esculturas (RICOEUR, 1976, p. 32-33).

As mudanças mais significativas operadas pela escrita no funcionamento do discurso ocorrem, porém, na relação mensagem-referencial. No discurso oral, o critério último para o escopo referencial do que se diz é a possibilidade de se mostrar a coisa referida como um membro da situação comum ao locutor e ao ouvinte. Tal situação rodeia o diálogo e os seus pontos de referência podem ser indicados por um simples gesto ou um apontar de dedo. É esse fundamento referencial da situação dialógica que é abalado pela escrita: a ausência de uma situação comum gerada pelo distanciamento entre escritor e leitor, o cancelamento do aqui e agora absoluto do diálogo oral, a autonomia semântica do texto; "todas essas alterações da constituição temporal do discurso são refletidas em alterações paralelas do caráter ostensivo da referência" (RICOEUR, 1976, p. 34-35).

Na comunicação oral, em que a produção do texto coincide com a prolação, os indícios paralinguísticos (como o tom da voz, os gestos ou as expressões faciais) podem bastar para determinar a intenção textual. $\mathrm{Na}$ comunicação escrita, porém, a determinação da intenção depende inteiramente dos elementos intrínsecos ao texto (SIMIAN-YOFRE, 2000, p. 163). Além do mais, o texto escrito, diferentemente do texto oral, pode prever leitores e contextos referenciais diferentes do aqui e agora; podem ter relação com certa "distância comunicativa" de diversos tipos: situacional, cultural e outras (GRILLI, 2002, p. 672).

\footnotetext{
${ }^{2}$ Poemas, narrativas e ensaios são exemplos de obras de discurso e os gêneros literários são as normas técnicas que presidem a sua produção.
} 


\section{Teoria dos atos linguísticos}

Obara avalia que o pensamento de John L. Austin - particularmente o seu conceito de ato linguístico como ação executada pelo locutor durante a enunciação - contribuiu grandemente para o aprofundamento do aspecto estratégico e funcional do uso da linguagem e, portanto, da comunicação (OBARA, 2010, p. 31-32). A teoria dos atos linguísticos de Austin parte da distinção entre ato locutório, ilocutório e perlocutório. $\mathrm{O}$ ato locutório corresponde a "dizer algo": "dizendo, realizamos atos locutórios, que equivalem, a grosso modo, a proferir certa sentença com certo sentido e referência que, outra vez a grosso modo, equivale ao 'significado' no sentido tradicional". O ato ilocutório é "aquilo que se faz", ao se dizer algo: "também realizamos atos ilocutórios tais como informar, ordenar, avisar, comprometer-se [...] enunciados que têm certa força (convencional)". O ato locutório associado ao ilocutório pode gerar no interlocutor um ato perlocutório ${ }^{3}$ : "também podemos realizar atos perlocutórios, que provocamos ou alcançamos ao dizermos algo, tais como convencer, persuadir, dissuadir e até mesmo, digamos, surpreender ou enganar" (AUSTIN, 1962, p. 108).

A teoria de Austin recebeu um contributo especial da parte de John R. Searle que, ao invés de classificar os atos linguísticos em locutórios, ilocutórios e perlocutórios, prefere falar de atos de emissão (emitir palavras [morfemas, orações]), proposicionais (referir e predicar) e ilocutórios (enunciar, perguntar, mandar, prometer etc.) (SEARLE, 1994, p. 32-33). Searle também argumenta que a tentativa de Austin de classificar os atos ilocutórios é defeituosa por diversas razões, especialmente pela falta de critérios claros para distinguir um tipo de força ilocutória da outra. Assim, o filósofo de Berkeley propõe subdividir o ato ilocutório em cinco tipos, segundo a modalidade de adaptação que se estabelece entre a linguagem e a realidade: "representativos (ou assertivos), diretivos, comissivos, expressivos e declarativos" (SEARLE, 1976, p. 1) . Essa proposta tornou-se um ponto de referência para a maioria dos autores.

Através dos atos representativos, o locutor procura descrever a realidade (ex.: ao afirmar, negar, concluir, crer). Por meio dos atos diretivos, o locutor busca induzir o ouvinte a fazer alguma coisa, a assumir determinada ati-

\footnotetext{
${ }^{3} \mathrm{O}$ ato perlocutório representa o efeito que a ação do emissor produziu sobre o destinatário e dificilmente encontra expressão sobre o plano linguístico (OBARA, 2010, p. 32).

${ }^{4}$ Sobre o uso da linguagem, Searle declara: "Se adotarmos o ponto ilocutório como a noção básica para classificar o uso da linguagem, então existe um número bastante limitado de coisas básicas que podemos fazer com a linguagem: nós dizemos às pessoas como as coisas são, nós tentamos levá-las a fazer coisas, nós nos comprometemos a fazer coisas, nós expressamos nossos sentimentos e atitudes e nós provocamos mudanças através dos nossos enunciados" (SEARLE, 1981, p. 29).
} 
tude ou conduta (ex.: ao ordenar, pedir, desafiar, insistir). Nos atos comissivos, ao contrário dos anteriores, é o locutor que se empenha em assumir determinada conduta (ex.: ao prometer, garantir, jurar, empenhar-se). Os atos expressivos são aqueles por meio dos quais o locutor expressa, ante determinado evento, os próprios sentimentos, o próprio estado psicológico (ex.: ao agradecer, desculpar-se, deplorar, congratular-se). Finalmente, por meio dos atos declarativos, o locutor altera o status de um objeto ou de uma situação, pelo simples fato de proferir um enunciado (ex.: ao declarar guerra, declarar um casal como marido e mulher, absolver, condenar) ${ }^{5}$. Frequentemente, realizamos mais do que um desses atos de uma só vez no mesmo enunciado (SEARLE, 1981, p. 29).

Searle alude também aos casos de atos linguísticos indiretos, nos quais um ato ilocutório é realizado indiretamente, por meio da execução de outro. Por exemplo, um locutor formula a sentença: "Quero que faças isso!", pedindo ao ouvinte para que faça algo. $\mathrm{O}$ enunciado é propositadamente apresentado como uma afirmação, mas ele tem o valor de um pedido, embora não esteja formulado como tal. Outro exemplo é quando se diz: "Você poderia me passar o sal?", sem que isso signifique uma mera pergunta, mas um verdadeiro pedido (SEARLE, 1981. p. 31). Quando a força ilocutória não pode ser determinada pelo verbo performativo ou pela forma do enunciado, tem-se então um caso de ato linguístico indireto (BOTHA, 1991, p. 286.). Trata-se de um enunciado cuja forma linguística, tomada em sua literalidade, caminha em uma direção, enquanto o seu escopo ilocutório segue por outro caminho. Isso acontece com frequência na cotidianidade e em todos os níveis (GRILLI, 2013, p. 531).

\section{Abordagem pragmalinguística}

Os atos linguísticos constituem a unidade básica de estudo da chamada "linguística pragmática" ou "pragmalinguística" (GRILLI, 2002, p. 663). Teun van Dijk explica que "a [linguística] pragmática [...] dedica-se à análise dos atos linguísticos e, de maneira mais geral, das funções dos enunciados linguísticos e de suas características nos processos de comunicação" (DIJK, 1992, p. 79). Essa ciência analisa os textos enquanto ações ou, pelo menos, enquanto instrumentos eficazes para produzir uma ação subsequente (BERGES, 1993, p. 85-86). Seu foco investigativo se volta para a função dinâmica dos textos, isto é, para as orientações e diretivas que eles dão ao leitor (EGGER, 1994, p. 130). Além disso, segundo a concepção da pragmalinguística, o emissor e o destinatário encontram-se "fossilizados" para sempre no próprio texto: eles não desaparecerão enquanto o texto

${ }^{5}$ O parágrafo combina, até aqui, GRILLI, 2013, p. 530, com OBARA, 2010, p. 33. 
existir. A qualidade de "estar no texto" é descrita através das categorias “autor/leitor implícito ou modelo" (BERGES, 1993, p. 83).

\subsection{Análises sintática, semântica e pragmática}

A subdivisão da semiótica em sintaxe, semântica e pragmática - proposta por Charles W. Morris (NEURATH; CARNAP; MORRIS, 1938, p. 79-137) - tem fornecido a base metodológica para a abordagem pragmalinguística de textos bíblicos. As três dimensões não podem, porém, ser tomadas como três âmbitos separados, em esplêndido isolamento, mas como três perspectivas em relação dialógica, ao interno do único processo comunicativo (GRILLI, 2013, p. 538). De fato, a consideração dessas dimensões tem uma finalidade, sobretudo, de tipo heurístico e convencional. Deve-se evitar, portanto, pensar que as análises sintática, semântica e pragmática constituam três passos perfeitamente distintos e sequenciados. Ademais, o aspecto pragmático já se faz notar desde o início da análise de um texto e a semântica está ligada a muitos fenômenos nos quais é difícil discernir entre as suas fronteiras e as da pragmática (PAZ; GRILLI; DILLMANN,1999, p. 46-47). Aliás, a semântica moderna nem mais considera o significado como um conceito autônomo, já que ele só existe em relação a uma situação determinada ${ }^{6}$. A divisão que os estudiosos costumam fazer da abordagem pragmalinguística em três etapas é aceitável, sobretudo, por razões de clareza metodológica.

Enquanto etapa metodológica, a análise sintática indaga acerca das articulações formais do texto (GRILLI, 1992, p. 24). Nesse estágio, estudam-se as relações que fazem de um texto um sistema arquitetônico complexo e coerente, uma unidade comunicativa estruturada e harmônica (PAZ; GRILLI; DILLMANN, 1999, p. 36). A própria natureza da investigação exige que a análise sincrônica seja priorizada e que, por isso, ocupe espaço e posição relevantes na discussão ${ }^{7}$. A atenção se volta especificamente à delimitação do texto, ao uso dos vocábulos, às formas estruturantes e às associações de palavras e frases das quais o autor se serve para dar ao texto uma sistematização orgânica. A relação recíproca dos elementos da estrutura é analisada não em nível "profundo", mas apenas em nível de "superfície" 8 . No caso específico da narrativa, analisa-se também a estrutura formal do relato e se busca chegar a uma divisão do mesmo, com base em indícios

\footnotetext{
${ }^{6}$ Por isso, os estudiosos de linguística da atualidade tendem prevalentemente a tomar a pragmática não como um âmbito, mas como parte integrante de cada fase da investigação. Cf.: GRILLI, M. Comunicazione e pragmatica. Disponível em: <http://www.evangeliumetcultura.org/italiano/Comunicazione-e-Pragmatica>. Acesso em: 21 nov. 2016.

7 "A linguística pragmática embasa-se sobre a sintaxe da obra, vista como um conjunto. Por isso, esclarece e confirma que a análise sincrônica é o passo fundamental de toda a análise do texto enquanto unidade literária" (LENTZEN-DEIS,1992, p. 735).

${ }^{8}$ Os critérios de organização não são primeiramente de ordem conceitual, mas gramatical, sintático e estilístico (GRILLI, 1993, p. 457).
} 
estruturais tais como repetição de palavras, inclusões, mudança de espaço ou de tempo e introdução de novos personagens (BERGES, 1991, p. 370).

A análise semântica investiga as relações formais existentes entre os sinais linguísticos e o seu conteúdo, bem como as combinações de significados entre palavras, frases e textos (GRILLI, 1992, p. 26-27). Depois de se ter analisado a forma externa dos sinais linguísticos, passa-se a relacionar tais sinais com a realidade extralinguística. Nessa etapa da investigação exegética, busca-se o significado das palavras e do texto: sem entender as palavras não se pode entender um texto; sem o significado do texto não se entende o significado das palavras e sem o conhecimento do contexto cultural não se pode entender corretamente um texto (BERGES, 1991, p. 370). A análise semântica de um texto bíblico deve levar em conta o contexto no qual ele se encontra inserido, o fundo cultural no qual ele se move, a comparação com passagens afins, a redação, o significado que provém do conjunto da obra às palavras e proposições e outros elementos (GRILLI, 1993, p. 458).

Adentra-se o campo da análise pragmática no momento em que se indaga acerca dos objetivos e propósitos das ações semânticas (PAZ; GRILLI; DILLMANN, 1999, p. 54). Nessa etapa investigativa, analisa-se a relação entre os sinais linguísticos e os seus usuários (emissor e destinatário) ${ }^{9}$. Os componentes do texto, que antes foram analisados em termos sintáticos e semânticos, são entendidos agora não mais como testemunhas de uma articulação formal ou de um sistema "objetivo" de informações, mas sob o aspecto funcional, do ponto de vista do uso por parte dos seus usuários. Busca-se aqui compreender a trama dialógica que se estabelece entre o autor e os seus leitores: as perguntas às quais o texto responde, como se identificam os destinatários, qual estratégia o autor persegue para motivar e conduzir os seus leitores a se identificarem com os modelos propostos no texto (GRILLI, 1992, p. 27).

Semântica e pragmática, embora estejam estreitamente correlacionadas, mantêm cada uma a sua especificidade. Ainda que o objeto estudado por ambas seja o mesmo, a perspectiva sob a qual se avalia tal objeto é diferente: a semântica pergunta-se sobre "o que isto quer dizer", enquanto a pragmática interroga-se sobre "o que se quer dizer com isto". Assim, a semântica procura compreender o que o emissor expressou, enquanto a pragmática ocupa-se das funções, intenções, metas e efeitos dos enunciados (GRILLI, 1993, p. 455). Pode-se dizer, de uma maneira sucinta, que a sintaxe examina a coesão do texto (conexões entre as partes de um texto, realizada através de vários elementos de ordem linguística, lexical, gramatical e sintática), enquanto a semântica avalia a sua coerência (a articulação

${ }^{9}$ Porém, a pragmática é bem mais do que simplesmente a última etapa da investigação, pois sem ela não existem sintaxe nem semântica (BERGES, 1993, p. 85). 
e o desenvolvimento dos conteúdos ou, melhor ainda, dos "motivos" que constituem o "tema" semântico do texto ${ }^{10}$ ) e a pragmática descobre a sua finalidade (finalidade agente) (GRILLI, 2013, p. 534-538).

\subsection{Autor e leitor implícitos}

Quando se analisa um escrito como um evento comunicativo, a questão referente ao autor se desloca do autor concebido em sua existência física e histórica, para o autor entendido como "estratégia textual"11. Tal princípio se aplica igualmente à questão referente ao leitor. Na abordagem pragmática, o autor e o leitor são considerados implícitos no sentido de que ambos encontram-se inscritos no próprio texto, na forma de pressuposições ou de consequências assumidas como comuns. O leitor implícito é aquele pretendido pelo autor que, ao escrever, atribui qualidades reais ou ideais aos seus destinatários e as exprime na forma de linguagem (GRILLI, 1993, p. 452). Portanto, o autor e o leitor com os quais se depara o leitor empírico não são aqueles reais, mas principalmente aqueles que aparecem no texto: são "figuras literárias"12.

\subsection{Estratégias comunicativas}

Em vista de atingir o seu objetivo comunicativo, o autor de um texto lança mão de uma série de estratégias, pressupondo um modelo de leitor capaz de percebê-las. A construção do leitor implícito é a estratégia fundamental através da qual se exprime o projeto global do texto, isto é, a sua função comunicativa e a sua própria eficácia operativa. Um texto prevê o seu leitor, que é o seu destinatário ideal, aquele para o qual a comunicação pode ser considerada como bem sucedida. De fato, afirmar que o texto é uma unidade de comunicação significa reconhecer que, já desde o início, o seu autor tem em vista os destinatários, aqueles que serão chamados a responder ao seu apelo (FUMAGALLI, 2000, p. 49) ${ }^{13}$. Por ser o texto obra

\footnotetext{
${ }^{10}$ Chama-se aqui de "tema" ao "tema de fundo", isto é, à matéria a ser elaborada ao longo do discurso, produto da interação de todos os motivos temáticos presentes no discurso. Os chamados "motivos" correspondem aos "temas particulares", isto é, às unidades significativas mínimas do tema, aos elementos repetidos ao longo do discurso. Os temas são principalmente de caráter metadiscursivo, enquanto os motivos "se manifestam de maneira mais evidente sobre a superfície do discurso - graças, por exemplo, à evocação dos elementos recorrentes, determinados termos ou imagens - pelo que a sua individuação e denominação resultam mais evidentes" (OBARA, 2010, p. 23-24).

${ }^{11}$ Obara, por exemplo, ao discutir as dinâmicas comunicativas dos discursos do Trito-Isaías (Is 56-66), identifica tal estratégia com IHWH, "que fala em primeira pessoa, assumindo as características do emissor da mensagem e, portanto, de destinador ou de autor modelo [...] [o que] relativiza o interesse pelo autor real ou empírico" (OBARA, 2010, p. 17-18).

${ }^{12}$ GRILLI, Pragmatica e analisi, não paginado.

${ }^{13}$ Ao tratar do leitor modelo, Umberto Eco afirma que "um texto é um produto cuja sorte interpretativa deve fazer parte do próprio mecanismo generativo" (ECO, 2000, p. 54, grifo do autor).
} 
conjunta do autor e do leitor, podem-se reconstituir, por meio do próprio texto, as intenções do autor e os condicionamentos e expectativas do leitor, bem como a situação comunicativa (PAZ; GRILLI; DILMANN, 1999, p. 25).

As estratégias comunicativas textuais correspondem aos aspectos fonéticos, lexicais, sintáticos, contextuais, retóricos e outros, que dão ao leitor as chaves não somente da compreensão do sistema transmissor, mas também as implicações pragmáticas desse mesmo sistema (GRILLI, 2002, p. 665). Pertence à competência textual do leitor implícito reconhecer o gênero literário do texto ${ }^{14}$, bem como a função de certos elementos linguísticos e parâmetros extralinguísticos que influenciaram certas escolhas da parte do autor. Pode-se dizer que o autor prefigura o seu modelo de leitor, elegendo-o como o seu interlocutor privilegiado, ou seja, como aquele que é capaz de compreender e executar as suas instruções ${ }^{15}$. Seguindo as estratégias comunicativas, gravadas na sintaxe e na semântica, o leitor empírico encontra-se com o leitor implícito e chega à investigação pragmática do texto, isto é, a uma investigação contextualizada (BERGES, 1993, p. 84-85).

O código, definido como o sistema de sinais por meio do qual a mensagem é transmitida, encerra em si determinada estratégia comunicativa: a habilidade de quem escreve se mostra através da criação de um sistema de sinais que prenda a atenção de quem lê e obtenha o seu assentimento. Da parte do leitor, compreender o código/sistema de sinais que transmite o significado constitui o sine qua non da comunicação. Em uma comunicação de tipo pragmático, pertencem a esse sistema de sinais os chamados "caracteres indiciais", que o emissor utiliza para se comunicar com o destinatário. No caso da comunicação escrita, os caracteres indiciais permanecem essencialmente as categorias clássicas: gramaticais, sintáticas, narrativas, de gênero literário, de tipo retórico e estilístico, repensadas, porém, em chave comunicativa (GRILLI, 2002, p. 672-673).

São considerados elementos reveladores da estratégia do autor, para motivar o leitor a adotar determinado modelo operativo: os tipos de locuções utilizadas (ex.: discurso direto ou indireto, ou então locuções assertivas, diretivas e performativas) e os indicadores de força (force-indicating-devices: os vários tipos de entonação, os modos dos verbos, as construções do enunciado, a posição dos advérbios e adjetivos, a valência comunicativa dos gêneros literários, das metáforas, dos elementos retóricos de um discurso ou do papel dos personagens em um relato). Enfim, a análise desses

\footnotetext{
${ }^{14}$ A identificação do gênero literário de um texto desperta no leitor determinadas expectativas, ao mesmo tempo em que o prepara para aderir a uma nova percepção dos eventos com que se depara. No caso particular de um texto apocalíptico, por exemplo, o gênero "despertará no leitor um conjunto de expectativas e de atitudes que o ajudarão a ler o momento de crise em que eventualmente se encontre e a fazer-lhe frente" (GRILLI, 2004, p. 105).

${ }^{15}$ GRILLI, Pragmatica e analisi, não paginado.
} 
elementos visa a demonstrar, especialmente, as indagações do leitor e as respostas que o texto lhe dá; as repercussões que o texto deseja provocar no leitor e o "modelo" (critérios e normas do agir) que este pode encontrar no texto (GRILLI, 1993, p. 458).

\section{Conclusão}

O valor pragmático da Palavra contida na Escritura não é uma descoberta recente, já que a própria Escritura e a Tradição ressaltam constantemente que a Palavra não retorna a Deus sem ter produzido o seu efeito (cf. Is 55,11). Recente é, ao invés, a aplicação da pragmalinguística ao estudo dos textos bíblicos e aos relativos contextos nos quais ocorre o evento comunicativo da leitura (GRILLI, 2002, p. 663). Os autores bíblicos, quando transmitem informações teológicas sobre Deus, sobre a sua ação salvífica e sobre a história, na verdade, intentam oferecer ao leitor uma "série de razões e motivos" para a ação (LENTZEN-DEIS, 1992, p. 734). Os textos bíblicos buscam levar o próprio leitor a se identificar com as soluções e valores que eles propõem. Pode-se dizer, em uma linguagem mais direta, que o objetivo último dos textos bíblicos é ditar modelos, uma vez que eles se apresentam como critério e norma do agir (GRILLI, 1993, p. 455). Portanto, a aplicação da pragmalinguística à Bíblia mostra-se bastante adequada.

Além disso, a adoção de uma abordagem pragmática da Bíblia tem contribuído consideravelmente na recomposição da fratura criada entre exegese, pensamento teológico e modelos de ação pastoral (GRILLI, 1993, p. 459). Ulrich Berges observa oportunamente que a Bíblia nos interessa em primeiro lugar na pastoral, porque nos oferece modelos de ação para os dias atuais, e que a análise pragmática nos transporta do texto antigo às exigências da atualidade (BERGES, 1991, p. 371). O mesmo autor em outra obra, depois de apontar algumas das diversas vantagens que a pragmalinguística oferece à exegese bíblica, conclui dizendo que "uma vez estabelecido o conteúdo, a intencionalidade e o efeito de um texto bíblico, o teólogo tem pautas mais seguras para a aplicação e atualização do mesmo" (BERGES, 1993, p. 90).

\section{Referências}

AUSTIN, J. L. How to do things with words: the William James lectures delivered at Harvard University in 1955. Oxford: Clarendon Press, 1962.

BERGES, U. Lectura pragmática de 1Sm 12. Revista Teológica Limense, Lima, v. 25, n. 3, p. 368-388, 1991. 
La lingüística pragmática como método de la exégesis bíblica. Revista Teológica Limense, Lima, v. 27, n. 1, p. 64-90, 1993.

BOTHA, J. E. The potential of speech act theory for New Testament exegesis: some basic concepts. Hervormde Teologiese Studies, Pretoria, v. 47, n. 2, p. 277-293, 1991.

DIJK, T. A. van. La ciencia del texto: un enfoque interdisciplinario. 3.ed. Barcelona: Paidós, 1992. (Paidós Comunicación, 5).

ECO, U. Lector in fabula: la cooperazione interpretativa nei testi narrativi. 7.ed. Milano: Tascabili Bompiani, 2000. (Saggi, 27).

EGGER, W. Metodologia do Novo Testamento: introdução aos métodos linguísticos e histórico-críticos. São Paulo: Loyola, 1994.

FUMAGALLI, A. Gesù crocifisso, straniero fino alla fine dei tempi: una lettura di Mt 25,31-46 in chiave comunicativa. Frankfurt am Main: Peter Lang, 2000.

GRILLI, M. Comunità e missione: le direttive di Matteo: indagine esegetica su Mt 9,35-11,1. Frankfurt am Main: Peter Lang, 1992.

Autore e lettore: il problema della comunicazione nell'ambito dell'esegesi biblica. Gregorianum, Roma, v. 74, n. 3, p. 447-459, 1993.

Evento comunicativo e interpretazione di un testo biblico. Gregorianum, Roma, v. 83, n. 4, p. 655-678, 2002.

A transfiguração do caminho: leitura de Mc 9,2-13 a partir da sua instância comunicativa. Revista Eclesiástica Brasileira, Petrópolis, v. 64, n. 253, p. 75-106, jan. 2004.

Parola di Dio e linguaggio umano: verso una pragmatica della comunicazione nei testi biblici. Gregorianum, Roma, v. 94, n. 3, p. 525-547, 2013.

Comunicazione e pragmatica. Disponível em: $<$ http://www.evangeliumetcultura.org/italiano/Comunicazione-e-Pragmatica>. Acesso em: 21 nov. 2016.

Pragmatica e analisi del testo. Disponível em: <http://www.evangeliumetcultura.org/IT/Pragmatica \%20e\%20analisi\%20del\%20testo.php>. Acesso em: 21 nov. 2016.

GRILLI, M.; GUIDI, M.; OBARA, E. Comunicazione e pragmatica nell'esegesi biblica. Roma: Gregorian \& Biblical Press, 2016.

JAKOBSON, R. Linguística e comunicação. São Paulo: Cultrix, 2008.

LENTZEN-DEIS, F. Metodi dell'esegesi tra mito, storicità e comunicazione: prospettive "pragma-linguistiche" e conseguenze per la teologia e la pastorale. Gregorianum, Roma, v. 73, n. 4, p. 731-737, 1992.

NEURATH, O.; CARNAP, R.; MORRIS, C. W. (Ed.). International Encyclopedia of Unified Sciences. Chicago: University of Chicago Press, 1938. v. 1, n. 2.

OBARA, E. M. Le strategie di Dio: dinamiche comunicative nei discorsi divini del Trito-Isaia. Roma: Gregorian \& Biblical Press, 2010. (Analecta Biblica, 188).

PAZ, C. M.; GRILLI, M.; DILLMANN, R. Lectura pragmalingüística de la biblia: teoría y aplicación. Estella: Verbo Divino, 1999. 
PONTIFÍCIA COMISSÃO BÍBLICA. A Interpretação da Bíblia na Igreja. São Paulo: Paulinas 1994.

RICOEUR, P. Interpretation theory: discourse and the surplus of meaning. Fort Worth: Texas Christian University Press, 1976.

SEARLE, J. R. A classification of illocutionary acts. Language in Society, Cambridge, v. 5, n. 1, p. 1-23, Apr. 1976.

Expression and meaning: studies in the theory of speech acts. Cambridge: Cambridge University Press, 1981.

- Actos de habla: ensayo de filosofía del lenguaje. Barcelona: Planeta De Agostini, 1994.

SIMIAN-YOFRE, H. (Org.). Metodologia do Antigo Testamento. São Paulo: Loyola, 2000.

Artigo submetido em 06.05.2019 e aprovado em 22.07.2019.

Clodomiro de Sousa e Silva é doutor em Teologia Bíblica pela Faculdade Jesuíta de Filosofia e Teologia (FAJE - 2017), diretor e professor titular do Instituto Católico de Estudos Superiores do Piauí (ICESP). Orcid.org/0000-0001-6360-9575. E-mail: csilva220574@gmail.com

Endereço: Av. Zequinha Freire, 375 - Condomínio Delta do Parnaíba

Bloco Igaraçu, Apto. 401

Santa Isabel

64069020 Teresina - PI 